\title{
Atender el grito de las y los pobres. El seguimiento del Señor Jesús que hay en cada mártir
}

\author{
Raúl Vera López, O.P. \\ Obispo de Saltillo, Coahuila (México).
}

Para comprender las palabras del Señor Jesús en la Última Cena, las mismas que recordamos en la Eucaristía: "Esto es mi sangre, la sangre de la Alianza, que será derramada por una muchedumbre" (Mc 14, 24), hay que mencionar a los profetas antiguos, pero también a los actuales, pues la Iglesia es el pueblo de Dios, la Iglesia "somos los que hemos bebido y abreviado el evangelio". Entre los contemporáneos están mujeres y hombres que buscan la verdad y la justicia, y que al enfrentarse al poder y buscar la vida, sus derechos, el derecho de la madre tierra, u otros, se los insulta y descalifica, son "levantados", desaparecidos, torturados y asesinados, donando su vida para que esta sea multiplicada.

La muerte violenta de los profetas puede ser un marco referencial para interpretar la de Jesús, pero no su muerte, sino su vida, para motivarnos - no a exponernos y entregarnos para atemorizarnos y dejar de trabajar-, sino para actuar valiente y decididamente, y hacer lo que Romero en estas tierras: establecer el reino de Dios en el aquí y el ahora.

Si se calla el cantor, calla la vida

porque la vida, la vida misma es todo un canto.

Si se calla el cantor, muere de espanto

la esperanza, la luz y la alegría.

\section{Las consecuencias para Daniel, Amós y Jeremías, y el ejemplo de Esteban}

En los primeros capítulos del libro de Daniel, en un segmento profético que especialmente contiene una enseñanza religiosa (Dn 3, 1-30), encontramos cómo Sidrac, Misac y Abed Negó - valerosos jóvenes - , junto con el propio Daniel, animaron al pueblo a resistir espiritualmente y personalmente soportaron las amenazas de las autoridades para seguir siendo fieles a sí mismos y leales a su fe. 
Antes de negar e insultar a su Dios, se rehusaron a servir a otros dioses y a adorar la absurda riqueza y el brillo espectacular del oro, y fueron en contra del decreto del emperador e hicieron enfurecer al rey Nabucodonosor, quien no solo ordenó a sus hombres torturarles y arrojarles al horno, sino que, además, "ordenó que se calentara el horno siete veces más de lo corriente", quizás la máxima temperatura posible, pero parece que fue exagerado, porque las llamaradas también mataron a los fuertes hombres del ejército del propio rey (3, 1-33).

Daniel aconsejó al rey que reformara su vida, se arrepintiera de sus pecados y mostrara mayor misericordia hacia los pobres, mientras los ministros y gobernadores buscaban pretextos contra él - según ellos, cuidando los intereses de su majestad-, aunque no encontraban más que su fidelidad. Es así que le fabricaron un delito para convencer al rey de darle un castigo, por lo que este -aunque triste - dio la orden para que lo arrojaran al foso de los leones, mientras le dijo: "iQue tu Dios, al que sirves con tanto valor, te libre!" (Dn 6, 2-29).

¿Qué pasó con Amós? Uno de los profetas llamados menores, que para ejemplo mío era pastor, pero no solo eso, sino que era un hombre sencillo de campo con formación cultural de familia y un tipo muy directo para hablar (Am 7, 10-15). Condenaba categóricamente la corrupción de las élites, la injusticia social y la falta de compromiso de los ritos religiosos, pues a pesar de que el reino pasaba por un periodo de prosperidad, la generalidad del pueblo estaba sumergida en la miseria. Así, el lujo de unos era un insulto para las y los miles de pobres, que aumentaban día a día, y el culto religioso encubría el rechazo a Dios y la opresión de los hermanos. La gente se escandalizaba por su manera de hablar, pues se metía en cosas "que no eran de religión". Criticaba templos y palacios y prefería que fueran destruidos, pues habían sido construidos y se mantenían a costa de la esclavitud y la explotación, favoreciendo al pecado. Amós lo tenía claro: no servía a los intereses de la corte; era un hombre libre (4, $1-5 ; 5,7-15 ; 21-27 ; 6,1-7)$.

¿Qué pasó con Jeremías? Apedreado en Tafne de Egipto, parece que terminó aquel cariñoso hombre con tiernos sentimientos, que protestó por ser joven y no querer aceptar el plan de Dios $(c f$. Jer 1,6$)$, que le declaró a él, para que entendiéramos todas y todos: "Antes de formarte en el seno de tu madre, ya te conocía, antes de que tú nacieras, yo te consagré, y te destiné a ser profeta de las naciones" (Jer 1, 5). Él no quería denunciar, ni amenazar, ni dar fuertes mensajes de parte de Dios, pero fue seducido por la justicia y la fuerza de la verdad de su Dios (Jer 1,10), a tal grado que sentía como fuego ardiente en su corazón y sus huesos, y actuó por amor a su pueblo con las palabras que Dios puso en su boca $(1,9)$. Muchas veces fue amenazado de muerte por hablar y escribir contra el país y los gobernantes $(13,18-19 ; 20-27 ; 16,16-18)$, pero tomó "la fuerza del diamante", como Dios se lo prometió (1, 17-19), y predicó durante el tiempo de cinco reyes. Seguro que Jesús pensaba también en Jeremías cuando 
decía: "¡Jerusalén, Jerusalén, que matas a los profetas y apedreas a los que te son enviados!" (Lc 13, 34).

Antes de morir lapidado por el pueblo fuera de la ciudad, Esteban preguntó: “HHubo algún profeta que sus padres no hayan perseguido?” (Hch 7, 52). Pensemos en los golpes de Sebastián, en las decapitaciones de Matías y Pablo, en el fuego en que murió Vicente, en el árbol de olivo en que murió Lucas, o en la caja de aceite hirviendo en que torturaron a Juan... Tanto en el Antiguo como en el Nuevo Testamento se menciona a los líderes que pedían al pueblo tener una actitud crítica frente a su vida, a tener en cuenta las consecuencias sociales de sus actos y les solicitaban poner en manos de Dios sus vidas, porque enfrentaban a autoridades civiles y religiosas, que los perseguían y asesinaban. "Archivos de la verdad escritos con letras de sangre" dice la Iglesia para hablar del extremo al que fueron llevados quienes dieron testimonio de su fe en esas condiciones.

Si se calla el cantor, se quedan solos

los humildes gorriones de los diarios, los obreros del puerto se persignan, quién habrá de luchar por su salario.

\section{El profeta Jesús a quien seguimos}

¿Y qué pasó con el Señor Jesús, con quien todas estas personas y muchísimas más, caminaban? El sumo sacerdote abiertamente dijo que a raíz de la resurrección de Lázaro, toda la gente estaba siguiendo a Jesús, por lo que tenían que acabar con él, pues los romanos irían a atacar al pueblo. Mejor que muriera uno y no todo el pueblo (Jn 11, 45-53).

El profeta no siempre dice lo que es agradable para escuchar, anuncia la verdad y esta suele ser intolerable. Dado que no se puede eliminar la verdad, se elimina a quien la transmite. Matando al profeta, se cree que se redime la incomodidad que la verdad desafía. El efecto es lo que molesta, no se los asesina por odio a Dios, sino por la pérdida de control.

La búsqueda de la justicia para que los hombres sean libres, para que las viudas no sean explotadas, para que las y los huérfanos no sean engañados es sobre lo que los profetas hablan claramente. El cesar el abuso contra las personas vulnerables y la protección de estas molesta a las autoridades del mundo judío o cristiano, del antes o del hoy. Entonces, no es odio a Dios, ni es odio a Jesús, el que lleva al martirio a los mártires, como a Don Óscar Arnulfo Romero, a los jesuitas de la UCA y a muchas y muchos latinoamericanos más, sino la pérdida de poder y la inestabilidad de sus intereses. Es la explotación con todo lo que esto lleva de réditos, la explotación de personas y del pueblo.

Los profetas son simultáneamente personas de denuncia y de conflicto, que abren un horizonte diferente y ofrecen esperanza, pues proclaman el cambio 
profundo de la historia que Dios quiere y lo propician por medio de quienes les escuchan y se ponen en acción para cambiar las condiciones actuales, y así hacer un mundo diferente, donde reinen la verdad y la justicia. Se dice que el profeta es el primero en escuchar y proclamar el verdadero sentido de la historia que Dios propone, como Jesús, profeta por excelencia, que anuncia y provoca el advenimiento del reino de Dios. Ya Daniel, profeta de la esperanza, por una visión anunció la llegada de un rey poderoso que enfrentará a los imperios que se construyen sobre cimientos de muerte y destrucción, representados también en sus visiones por bestias feroces, que sembraban la muerte a su alrededor (Dn 7, 1-14). Daniel, como todos los profetas del Antiguo y del Nuevo Testamento, no se ha quedado solamente en la denuncia, sino instituye escuelas proféticas, porque quien es profeta mantiene la vida en la tierra, ahora y en el futuro.

Qué ha de ser de la vida si el que canta

no levanta su voz en las tribunas

por el que sufre, por el que no hay

ninguna razón que lo condene a andar sin manta.

\section{Nuevas reacciones en la Santa Sede}

Es un cambio muy significativo que el papa Francisco reconozca los motivos verdaderos por los que Monseñor Romero se movió a defender la vida de su pueblo contra los abusos de un poder político coludido con el poder económico, que lanzaba al ejército y a la policía contra la ciudadanía, que exigía el respeto a los derechos inherentes a su dignidad como personas y como pueblo. No eran motivos políticos los que movían a Don Óscar, sino las entrañas de compasión, que lo impulsaban a defender la vida de las y los salvadoreños.

Hablo de cambio significativo porque, sin duda, desde dentro de la comunidad eclesial, sobre todo, entre quienes deberían decidir si la muerte de Don Óscar merecería que se considerara como un martirio, prevalecía una mentalidad semejante a la de los poderes político y económico. Por supuesto, el interés de esas personas de Iglesia coincidía con la "seguridad nacional", que se logra por los medios que sean, incluidos la represión y el asesinato. El riesgo de dar un "mal ejemplo" al pueblo, de que se puede discutir y contradecir a la autoridad pública, el riesgo de que la sociedad esté organizada y pueda provocar un desorden, el riesgo de desestabilizar al país, lo cual afecta al "progreso", todo esto lo hacían recaer sobre la persona del obispo. Es decir, la actividad pastoral de Don Óscar se leía desde esta perspectiva del poder, dentro de una maraña de intereses de todo tipo, que excluía su interés por la vida del pueblo, el valor primordial del obispo.

En esas excusas se basaban para afirmar que su asesinato no fue por odio a la fe, sino por causas políticas. Una persona no podía ser mártir si no había sido matada por el odio a la fe que profesaba; pero el odio a la fe lo entendían como 
odio directo a Jesucristo, el Hijo de Dios, y por lo tanto, la muerte se presentaba por un odio a Jesús, y solamente así, esa persona se hacía digna de ser considerada mártir. Pero alguien que se enfrenta al poder, "alguien que se enfrenta a nuestros amigos del gobierno y a los empresarios con quienes hicimos la lucha por acallarle desde la nunciatura apostólica y no nos hizo caso, ¿cómo vamos a declararlo santo? Cuando nosotros fracasamos para quitárselo de enfrente al grupo político que gobernaba en ese tiempo. No lo vamos a declarar santo". Eso es lo que sucedía dentro de la Iglesia, en el nivel oficial. Hoy es muy distinto. Están empezando a cambiar los parámetros para declarar mártir a una persona y esto es lo que se está atreviendo a hacer Francisco.

Mientras quienes estén al frente de la Iglesia vivan asociados con los poderes del mundo, no van a identificar a los discípulos de Cristo, que mueren por defender el verdadero orden social, que describe el evangelio del reino. Y como esos pobres hijos se enfrentan a los políticos, declaran desde las cúpulas que eso no es odio a la fe, ni a Jesús, sino que se está haciendo política. Por eso, el paso que hoy da la Iglesia es un avance muy amplio. Porque en algún momento se dijo que Don Óscar hizo política, lo cual permitió a la máxima instancia de la Iglesia tener en la congeladora su causa de beatificación, valiéndose de personas incoherentes con su fe, que no querían quedar mal ante los poderes del mundo, representados por toda clase de embajadores, a través de quienes se impidió que esa causa siguiera adelante. Todo ello a pesar de que el pueblo de Dios lo llamaba ya, extraoficialmente, san Romero de América y lo consideraba un mártir. Gracias a Dios, después de treinta y cinco años de haber sido asesinado un 24 de marzo, el papa lo proclamó mártir in odium fidei al inicio de este año y estamos a punto de celebrar su beatificación. Es un momento histórico no solamente para El Salvador, sino para toda la Iglesia. Estamos ante un hito, pues aquí se produce un parte aguas, en la comprensión de lo que significa el martirio.

Mientras la Iglesia ha estado ligada al poder, se ha escondido en la hipocresía de los fariseos y ha ocultado la justicia y la verdad. Y lo peor es que lo sigue haciendo, pues aunque tengamos en la Santa Sede a un pontífice humilde y sencillo, que ha preferido aparecer como un simple cristiano sin ostentar signos de poder, algunos miembros de la jerarquía seguimos dando tumbos. Como la Iglesia en México en este momento, que cuando el papa Francisco declara que nuestro país está sumergido en la violencia y la corrupción, utilizando incluso el término mexicanización para hablar de su preocupación por la escalada de la inseguridad, en su propio país, Argentina, el nuncio y el consejo permanente de la conferencia episcopal mexicana se apresuran a sentarse a almorzar con el Presidente de la República. Esta relación no es cosa del pasado, sino del presente más reciente, como para dar un ejemplo claro. Pues en México, algunos miembros de la jerarquía eclesiástica siguen pensando y repitiéndose a sí mismos que la Iglesia es poder. 
Si se calla el cantor, muere la rosa

de qué sirve la rosa sin el canto

debe el canto ser luz sobre los campos,

iluminando siempre a los de abajo.

\section{Miseria y abandono}

El proceso de explotación, de opresión y de exclusión al cual son sometidas las personas durante muchos años, acaban para convencerlas de que para ellas no existe otra posibilidad, que no son merecedoras de un trato diferente al que reciben.

Estas experiencias de trabajo con los despreciados de la tierra, unidas al control que los poderosos ejercen sobre ellos por años, sistemáticamente y sin posibilidades de que la persona pueda conocer otra manera de vivir con dignidad, van unidas a las prácticas religiosas opresivas, coludidas con los poderosos. Este conjunto de circunstancias forman parte de una de las explicaciones de por qué una parte del pueblo se pone de parte de quienes se oponen al justo, que se enfrenta a los poderosos. Estos hacen creer al pobre que el mínimo hálito de vida del que se les permite disfrutar lo tienen gracias a quien lo explota, pues, de otra manera, morirían de hambre y de frío sin un mínimo de comida y de techo.

Una razón muy poderosa por la cual los pobres muchas veces se oponen a quienes luchan por la liberación de personas y grupos vulnerables es la inhibición forzada de sus propios derechos, a la que se ven impulsados por el temor a que sus opresores los despidan de sus trabajos.

Existe también la manipulación de la pobreza de los partidos políticos, que se mantienen en el poder con programas de ayuda paliativa a estas mujeres y hombres en total desventura, cuya desgracia ellos mismos promueven y mantienen, desde su forma corrupta de gobernar. Esos grupos corruptos, a través de políticas públicas basadas en programas sociales clientelares, se erigen a sí mismos en protectores de las personas que viven en la periferia y el campo, que ellos multiplican, mediante políticas públicas con las cuales institucionalizan la inequidad y la desigualdad social. No solo aumentan rápidamente el número de pobres, sino que los convierten cada día en personas más miserables. Por otra parte, a costa de esa miseria de las personas despojadas, los ricos cada vez son menos numerosos y mucho más ricos. Las personas favorecidas con esos programas paliativos serán opositoras de quienes promueven procesos de liberación, por el hecho de que se oponen al poder establecido que les da de comer de vez en cuando y que las mantiene también en la ignorancia para que con mala información mediática sean fácilmente manipulables.

Otras razones por las cuales los pobres se oponen a la liberación de los pobres son los miedos a lo diferente y a la otredad, como, por ejemplo, la xenofobia, la homofobia, el racismo, la misoginia, etc. 
Que no calle el cantor porque el silencio

cobarde apaña la maldad que oprime,

no saben los cantores de agachadas

no callarán jamás de frente al crimen.

\section{Persecución del profeta por la soberbia acumulada}

¿Qué lleva a los "grandes", según sus propias razones, a perseguir a un justo? Es una mezcla de movimientos interiores y exteriores. Para cualquier persona con poder económico, político o religioso, el único camino para acrecentar y acumular ese poder es el acrecentamiento y la acumulación del propio yo dentro de su corazón, lo cual le conduce a acrecentar y acumular el desprecio a la persona humana de quien es pobre. Una pobreza que se expresa en cualquier condición humana, se trate de indígenas, mujeres y hombres campesinos, obreros, migrantes, habitantes de barrios populares, mujeres y niños o cualesquiera personas, sometidas a una condición de vulnerabilidad, que posibilite y haga accesible el camino para convertirlas en objeto de ganancia jugosa de cualquier tipo, al menor costo, con la mínima inversión e inclusive con todas las garantías de violentar sus derechos, dentro de un margen del 99 por ciento de posibilidades de permanecer impunes, ante los delitos que contra ellas cometan.

Esta soberbia ante ellas y ellos, y el desprecio hacia sus personas aumentan cuando se organizan para defender sus derechos y ponen al descubierto a los poderosos, ya se trate de políticos, de financieros, de empresarios o de líderes religiosos, coludidos con el poder, que terminan aliándose entre ellos para enfrentar a quienes defienden su dignidad y su vida. De este desprecio por las personas vulnerables para poder explotarlas y engañarlas, los poderosos pasan a la humillación de cualquier persona o grupo de personas que muestran una actitud solidaria con las víctimas de sus tropelías. En ese momento también las alianzas desde el poder se entrelazan para defender intereses de todo tipo, que sientan amenazados o afectados. Estos intereses son especialmente económicos, pero también amenazan y afectan el prestigio y la imagen personal o de grupos de diverso cuño, se trate de grupos empresariales o de partidos políticos.

Estas alianzas también asocian a líderes religiosos contaminados con una visión de poder mundano y que ejercen su ministerio de acuerdo a esa visión de poder. Pero esto se complica cuando no son solamente personas individuales quienes actúan como cómplices de ellos, sino que es una institución religiosa la que estructuralmente se hace cómplice del poder. Desgraciadamente, esto pasó con la Iglesia católica ante personas como Don Óscar Arnulfo Romero, que no es un caso excepcional en la Iglesia.

Es gravísimo cuando la vida de estos pastores está en riesgo, porque no es solamente la vida de ellos, sino la de sus ovejas, la que está expuesta a la destrucción por medio de detenciones arbitrarias, ejecuciones personales o de grupos y 
masacres de multitudes y pueblos enteros, como pasó en El Salvador, en tiempos de Monseñor Romero.

¿Cómo llegan los poderosos al asesinato de quienes se enfrentan a ellos al reclamarles sus injusticias? Hemos venido hablando del desprecio creciente hacia las personas de los pobres, que va invadiendo sus corazones. Esto abarca la ofensa de la vida toda de los pequeños, pues ya mantenerlos marginados como esclavos, negándoles sistemáticamente el acceso a sus derechos más fundamentales, es una manera cruel de arrebatarles la vida.

Esto va llevando al rico y al poderoso, e incluso a quien ostenta algún tipo de liderazgo a la manera del poder del mundo, que aplasta y humilla, a deshumanizarse y, por lo tanto, a acallar la voz de su conciencia con todo aquello que lo obliga a respetar los derechos más fundamentales de sus semejantes. Es decir, han llegado a silenciar su conciencia de tal manera que no solamente no se mueven para remediar la injusticia, sino que además la propician para provecho propio. Por ello, cuando se levanta la voz que denuncia al poderoso su injusticia, este no tolera que la voz de su conciencia que acalló dentro de él, surja desde fuera contra él. De modo que para acallar esa voz tiene que destruir a quien ha sido signo coherente, que habla en medio de sus injusticias.

Por eso Herodías, por medio de su hija, mandó asesinar a Juan el Bautista. Por eso, los asesinos de Esteban, el protomártir de la Iglesia, lo primero que hicieron fue taparse los oídos y gritar para no escuchar la denuncia del diácono, que les recordaba que nunca habían escuchado la voz de los profetas.

Que se levanten todas las banderas

cuando el cantor se plante con su grito

que mil guitarras desangren en la noche

una inmortal canción al infinito.

\section{Atender el grito de las personas}

Nosotras y nosotros entendemos el martirio como la entrega de la vida para que se realice el proyecto de Dios en el mundo, eso es lo que estaban buscando los profetas antes, aunque la Iglesia, insisto, lo pretenda ocultar y no quiera reconocerlo. Como decir que Romero no tenía presente a Cristo, cuando estaba enfrentando a los soldados, y que murió por enfrentarse al Estado y por mantener a la guerrilla, y no por un seguimiento del evangelio. Como si el Señor Jesús permitiera todo tipo de orden político como válido. Aquí era un pecado enfrentarse al gobierno, Don Samuel, en Chiapas -en el sureste mexicano-, era muy mal visto, porque se enfrentó a los políticos. Todo lo que los políticos iban a decir contra él era aceptado en la Santa Sede como palabra de Dios. La Iglesia se convirtió en un instrumento diplomático de Dios, de no incomodar a los poderosos ricos, ni a los poderosos políticos. Eso es lo que ha sido la Iglesia durante todos estos siglos, desde que decidió conformarse como una monarquía. 
Seguir a Cristo y proclamar su evangelio y luchar para que se viva, denunciando los abusos de un poder político criminal y de una manera de gobernar, que promueve la desigualdad y la miseria, y que aplasta con la fuerza militar a quien lucha por defender la justicia y el respeto a la dignidad de la persona humana, implica la condena de los poderosos, que se ven afectados. Por eso, condenarán a quien se enfrente a su modo de obrar, como lo manifiesta el libro de la Sabiduría al decir que les someterán al ultraje y al tormento "para conocer el temple de los justos, y probar su entereza". Ellos así discurren, pero se equivocan. Los ciega su maldad, no conocen los secretos de Dios, ni esperan recompensa por la santidad, ni creen en el premio de las almas intachables.

Como los antiguos profetas, que dieron origen a escuelas y procesos formadores de profetas, así también el legado de los profetas de nuestro tiempo inspira procesos organizativos de la Iglesia y de la sociedad, procesos que siguen alimentando la esperanza del pueblo y que continúan formando protagonistas de una historia, donde la dignidad humana es valorada con el respeto profundo a los derechos fundamentales que le son propios. La sociedad y las comunidades se convierten en espacios incluyentes abiertos a todas y a todos. El destino universal de los bienes de la tierra se respeta, porque la familia humana es solamente una y la única casa de ella es todo el planeta Tierra, donde todo lo que hay en él está destinado a la protección y promoción de la vida de todas y cada una de las personas que lo habitan. En América Latina, podríamos enumerar una larga lista de estas mujeres profetas y de estos hombres profetas, que han contribuido a hacer de nuestras comunidades pueblos enteros de anuncio y denuncia. Entre ellas y ellos están las hermanas de Maryknoll, Ita Ford y Maura Clarke y sus compañeras, martirizadas con ellas en El Salvador, Úrsula Dorothy Kasel y Jean Donovan, Don Óscar Arnulfo Romero, Don Samuel Ruiz García, Don Leónidas Proaño y Don Enrique Angelelli, para citar a algunas y algunos.

Ellas y ellos, y a quienes nos falta por citar, que trabajaron en medio de las mismas comunidades, estuvieron abiertos a escuchar el grito de quien sufre y padece las consecuencias de las injusticias, que las victimizan. En nuestra experiencia, en la diócesis de Saltillo, al escuchar el grito de los mineros del carbón, veinticinco de los cuales murieron en siniestros ocurridos en dos pozos, y de la explosión de una mina de arrastre con 65 mineros muertos, con la ayuda del Equipo Nacional de Pastoral Laboral, de un grupo de religiosas y de mineros y familiares de las víctimas, empezamos a organizar lo que es hoy el grupo "Familia Pasta de Conchos", un equipo que se ocupa de crear, en la región carbonífera del Estado, una cultura de la seguridad para las minas y tajos, y de monitorear los siniestros de la zona.

Al escuchar el grito de la comunidad LGBTTTI y de las personas discriminadas, insultadas, golpeadas y asesinadas, iniciamos el servicio pastoral, con todas las contrariedades que eso conlleva. Personas de la Santa Sede, basadas 
en una información totalmente distorsionada de dicho servicio, originada en un grupo de ultraderecha de Perú, intentaron destruir nuestro trabajo. Primero con calumnias mediáticas, luego con informaciones que pretendieron ser más formales. Lo denuncié ante el papa Francisco, en nuestra visita ad limina Apostolorum el año pasado. Teníamos un trabajo estupendo. Las circunstancias dividieron al grupo y nos ha costado mucho trabajo reconstituirlo, aun cuando no dejamos de prestar nuestro servicio. Así, hemos logrado incidir bastante en la mentalidad homofóbica de una cultura que desea rechazar al ser humano.

Al escuchar el grito de las personas afectadas por la desaparición forzada, hemos creado una red de familiares para buscar a sus desaparecidos, llamado Fundec, Familias unidas por sus desaparecidos en Coahuila. El trabajo de la red se realiza con una organización autónoma, pero está integrado al Centro Diocesano para los Derechos Humanos Fray Juan de Larios, fundado en la diócesis hace casi quince años, cuando llegué a ella. La red ha incidido en el gobierno estatal y federal para que se creen las leyes o se modifiquen las existentes, en torno a implementar la localización de las personas desparecidas. Se ha puesto a caminar un proceso de búsqueda de víctimas de desaparición forzada y nos hemos organizado para luchar contra la impunidad en la que quedan los delitos relacionados con esta violencia social.

Ante el grito de los migrantes, especialmente los centroamericanos, a raíz de tres asesinatos, de personas con sus extremidades, manos o pies, mutiladas y de la muerte de algunos arrollados por los trenes, a los cuales intentan subir o bajar o de los cuales son arrojados, a raíz de las extorsiones, los robos y las violaciones sexuales, sufridas tanto por mujeres como por varones, y a raíz del sufrimiento que padecen en su caminar, hemos organizado una pastoral migratoria, que les ofrece acogida para restaurar sus fuerzas, atención psicológica y médica para quien lo necesite, y apoyo espiritual. Defendemos sus derechos y tenemos trabajo de incidencia para tocar y remover las causas de la migración forzada. La diócesis de Saltillo ha montado dos casas para migrantes, una de ellas quedó en otra diócesis, al norte del Estado. Todas las casas del migrante de la República están organizadas en red y desarrollamos un trabajo de recíproca colaboración. Salimos juntos a defender a los migrantes para intentar revertir las causas injustas que provocan la migración.

En este trabajo están comprometidas muchas personas que, desde la base de estos organismos, soportan el peso del funcionamiento de cada uno de ellos y lo hacen con un espíritu de servicio ejemplar. En muchas ocasiones, realizan su trabajo en medio de riesgos tremendos y con un salario bajo.

Desde finales de septiembre de 2014, ante el caso tremendo de la desaparición de los 43 estudiantes de la normal rural Isidro Burgos de Ayotzinapa, en el Estado de Guerrero, los familiares de los desaparecidos -y además, tres asesinados, uno de ellos desollado: le arrancaron el rostro-, junto con miles de mexicanos, 
gritamos por todos los medios para que el gobierno que los capturó los presente vivos. El gobierno mexicano no tiene corazón y no tiene oídos para escuchar estos gritos. ¡Qué diferencia tan grande de actitud ante figuras tan extraordinarias como la de Don Óscar, la de Don Samuel, la de Don Enrique Angelelli, la de Don Leónidas Proaño, la de las hermanas de Maryknoll y sus compañeras, la de los padres Rutilio Grande, Ignacio Ellacuría y sus compañeros, y la de miles y miles de personas que, junto con ellas y ellos, supieron escuchar el grito del pobre y desprotegido y entregaron su vida por defender la vida de ellos! ¡Qué torpeza tan grande la de quienes, para justificar el sufrimiento que padecieron, siguen utilizando el mote de "los persiguieron y los mataron porque se metieron en política"! Quienes se atreven a manifestarse de esa manera pertenecen al grupo de aquellos calificados por los profetas como los que convierten al mal en bien y al bien en mal. 